\title{
Conceptualising and managing supervisory drift
}

\author{
Jason Roscoe \\ Institute of Health, University of Cumbria, Lancaster Campus, Bowerham Road, Lancaster, LA1 3JD, UK \\ ${ }^{\star}$ Corresponding author. Email: jason.roscoe@cumbria.ac.uk
}

(Received 23 May 2021; revised 14 October 2021; accepted 2 November 2021)

\begin{abstract}
Clinical supervision is widely considered to be an essential component in the translation of evidence-based treatment protocols into routine clinical practice. Experts in the field have produced guidance on the structuring of CBT supervision, yet previous surveys on everyday practices have consistently found that supervisors and supervisees appear to drift from these recommendations. Surprisingly, little has been written on the origins and maintenance of supervisory drift and thus it remains a poorly understood phenomenon. To assist supervisors, supervisees and meta-supervisors in recognising and responding to signs of drift, this paper seeks to build on the understanding of therapist drift by conceptualising how supervisor and supervisee cognitions, emotions and behaviour could intentionally or unintentionally render the supervision process ineffective or at worst harmful. Drawing on therapist schema literature, hypothesised pre-disposing factors for drift are presented together with clinical examples and a range of steps for managing indicators of drift in practice. Further research is needed to gather empirical support for the mechanisms proposed.
\end{abstract}

\section{Key learning aims}

As a result of reading this paper, readers should:

(1) Understand what supervisory drift is and the various forms it might take.

(2) Recognise some of their own behaviours within supervision which might affect the quality and effectiveness of supervision.

(3) Identify ways in which problematic elements of supervision could be addressed within supervision, or supervision of supervision (SoS), through the use of a bespoke formulation and action-based methods.

Keywords: CBT; competences; meta-supervision; reflection; supervisory drift

\section{Introduction}

Clinical supervision (CS) is an integral part of the working life of a cognitive behavioural therapist. It provides an opportunity for qualified supervisees and those in training to reflect upon their clinical skills and for supervisors to assist in skill development and refinement (Liness et al., 2019; Pugh and Margetts, 2020) and the monitoring of safe and ethical practice (Milne, 2017). CS has been defined as 'the formal provision, by senior/qualified health practitioners, of an intensive, relationship-based education and training that is case-focused and which supports, directs and guides the work of colleague/s (supervisees)' (Milne, 2007; p. 440). It is also a mandatory requirement for achieving and maintaining cognitive behavioural therapist (CBT) practitioner accreditation with the British Association of Behavioral and Cognitive

(C) The Author(s), 2021. Published by Cambridge University Press on behalf of the British Association for Behavioural and Cognitive Psychotherapies. This is an Open Access article, distributed under the terms of the Creative Commons Attribution licence (https:// creativecommons.org/licenses/by/4.0/), which permits unrestricted re-use, distribution, and reproduction in any medium, provided the original work is properly cited. 
Psychotherapies (BABCP) in the United Kingdom (Armstrong and Freeston, 2006; Corrie and Lane, 2015).

Given the importance that is placed on supervision by training institutions, employers, governing bodies and therapists themselves it is of concern that supervision in everyday practice does not always mirror the recommendations in the expert literature (Alfonsson et al., 2017; Townend et al., 2002; Weck et al., 2017: Younge and Campbell, 2013). For example, an online survey of $170 \mathrm{BABCP}$-accredited CBT therapists carried out by Townend et al. (2002) found that only $18 \%$ of respondents reviewed video or audio footage of therapy sessions with their supervisor. Other 'active' supervision methods such as role play were also comparatively uncommon (19\%) and the direct observation of skills (i.e. supervisor sitting in during a therapy session) was even rarer (6\%). In other studies, an over-reliance on case discussion has been identified (e.g. Weck et al., 2017; Younge and Campbell, 2013).

\section{Supervisory drift}

One of the potential consequences of inconsistent supervision practices is 'supervisory drift' (SD) (Grey et al., 2014; Pugh and Margetts, 2020). Whilst the issue of 'therapist drift' has received some attention in the extant CBT literature (Rameswari et al., 2021; Waller 2009), supervisory drift remains poorly understood in terms of its definition, prevalence, reasons for occurrence, identification in routine practice and potential solutions. This paper is an attempt to summarise what is known about this topic and to hypothesise potential causal mechanisms by drawing on existing supervision and interpersonal processes literature. It is also the intention to provide supervisors, supervisees and those that supervise supervisors, referred to henceforth as 'meta-supervisors' (Newman, 2013) with a resource to reflect on their practice or use of supervision.

Section 1 seeks to assist supervisors and supervisees in recognising the hallmarks of good quality supervision; in other words, how it should be done according to expert recommendations and the limited evidence base that exists thus far. By drawing upon general supervision literature and evidence-based CBT supervision, readers will be able to reflect on their own supervision practices and begin to identify indicators of drift. Section 2 will introduce a range of contextual and pre-disposing factors that both supervisor and supervisee bring with them into the supervisory relationship and which are hypothesised to play a role in the origins or maintenance of SD. By utilising the literature on therapist skill development, therapist drift and therapist schemas, a number of maladaptive assumptions involved in supervisory drift are hypothesised to lead to problematic supervisor and supervisee cognitions, emotions and behaviours (Bennett-Levy, 2006; Haarhoff, 2006; Leahy, 2001; Milne et al., 2009; Waller, 2009). The term 'supervision dyads' will be used to refer to the relationship between supervisor and supervisee, whilst also recognising that certain formats such as peer supervision often include more than two parties. Section 3 will then introduce a novel interpersonal process model of supervision to assist in formulating difficulties by using a number of fictional case studies to illustrate this. Finally, Section 4 will offer a range of potential solutions for how drift can be rectified.

\section{Section 1: Defining and recognising supervisory drift in everyday practice}

Little has been written specifically on drift within CBT supervision, with a search of the electronic databases PsycARTICLES, Medline, CINAHL and Academic Search Complete using the terms 'cognitive behavioural therapy' and 'supervisory drift' generating only one result. Pugh and Margetts' (2020) summary of action-based methods is the nearest to a clear definition where they suggest that supervisory drift 'refer to instances in which core components of supervision (e.g outcomes monitoring, direct observation, mutual feedback) are omitted, avoided or 
deprioritised, resulting in a gap between supervisory theory and practice' (p. 5). Hand searching by the author also found a Milne et al. (2009) case study on collusion which helps to provide a useful example of one way that drift may present in clinical practice. Using Pugh and Margetts (2020) as a working definition, this section will seek to define what these core components are in everyday supervision and how they might be intentionally or unintentionally omitted.

\section{The core components of supervision}

Kadushin (1968), writing in relation to social work supervision, was one of the first to offer a definition of the main purpose of supervision. Kadushin suggested that it serves three functions which are educative, supportive and managerial. Proctor (1994), applying these concepts to the counselling arena, described them as normative, formative and restorative. Within the realm of psychotherapy, the aim of the supervision process is to produce therapists that have 'confidence, competence and creativity' (Proctor, 1994; p. 309). In the process of fostering confident, competent and creative supervisees, the supervisor is likely to encounter doubt of their own and their supervisees' abilities, ethical challenges, organisational pressures and role conflicts, differences of opinion, training background, impasses and at times, ruptures in the supervisory relationship (Moorey and Byrne, 2019; Pugh, 2019a; Watkins, 2020; Wilcockson, 2020).

This suggests that on a day-to-day basis, the role of a clinical supervisor is one which requires a dynamic approach, where several 'hats' need to be rotated at any given time in response to the challenges that emerge. A competent supervisor will therefore be aware of when tensions might arise between the need to attend to restorative aspects of the role whilst maintaining a focus on the normative and formative elements. Based on these concepts, it is hypothesised that drift may be evident when there is too little focus on one of these domains (e.g. too little formative aspects) or too much of a restorative focus (e.g. allowing the supervisee to 'let off steam' about their organisation).

\section{Defining good quality CBT supervision}

Historically there has been a reliance upon expert consensus (Kennerley et al., 2017) and 'reflexivity' (Milne, 2008) whereby the process of supervision should mirror the process of therapy, with a clear and collaborative agenda, defined problems, specific goals and a review of learning (Beck and Beck, 1995; Cummings et al., 2015). To illustrate this in action, Gordon (2012) produced a helpful 'ten steps to supervision' paper and Pretorius (2006) conducted a literature review to establish some markers of best practice with his findings indicating that good quality supervision would include three main elements: (i) a recognised format, (ii) sessions tailored to the experience of the therapist, and (iii) the cognitions and emotions of supervisees would be explored. Examples of normative, formative and restorative duties that a CBT supervisor may undertake in line with the Gordon and Pretorius recommendations are captured in Table 1 adapted from a format presented originally by Hawkins and Shohet (2000).

\section{Evidence based clinical supervision (EBCS)}

Replicating many of the principles of CBT therapy has an appeal due to its apparent simplicity; however, there is the potential to overlook the key differences between the role of therapist and supervisor (Prasko et al., 2012) and supervisee and client (Milne, 2017). Furthermore, without a testable theory as to how supervision works, it is difficult to argue for the concrete benefits of certain supervision methods (e.g. role play) over others (e.g. case discussion). The work of Milne and colleagues (e.g. James et al., 2006; Milne and Dunkerley, 2010; Milne and Reiser, 2012) has been instrumental in developing a systematic fidelity framework that includes both 
Table 1. Primary foci of CBT supervision (adapted from Hawkins and Shohet, 2000)

\begin{tabular}{|c|c|}
\hline Main categories of focus & Clinical example \\
\hline Educational/formative & Helping supervisees to notice patterns in how they \\
\hline $\begin{array}{l}\text { To provide a regular space for the supervisees to reflect } \\
\text { upon the content and process of their work }\end{array}$ & $\begin{array}{l}\text { respond emotionally and behaviourally to different } \\
\text { clients through different forms of SP/SR (e.g. role } \\
\text { play, completion of automatic thought records) }\end{array}$ \\
\hline Educational/formative & Reviewing supervisee understanding of treatment \\
\hline To develop understanding and skills within the work & $\begin{array}{l}\text { models or specific interventions (e.g. Clark Panic model/ } \\
\text { practising interoceptive exposure with supervisor) }\end{array}$ \\
\hline Formative/restorative & Reviewing audio or video recordings of the supervisee's \\
\hline $\begin{array}{l}\text { To receive information and another perspective } \\
\text { concerning one's work }\end{array}$ & $\begin{array}{l}\text { clinical work/supervisor 'sitting in' on supervisee live } \\
\text { therapy session in person or online }\end{array}$ \\
\hline Formative/restorative & Formally marking a supervisee recording using the \\
\hline To receive both content and process feedback & CTS-R criteria (Blackburn et al., 2001) \\
\hline Restorative & $\begin{array}{l}\text { Review of progress using the Roth and Pilling } \\
\text { competences }\end{array}$ \\
\hline $\begin{array}{l}\text { To be validated and supported both as a person and as } \\
\text { a worker }\end{array}$ & $\begin{array}{l}\text { Supervisor helping supervisee to recognise own } \\
\text { strengths using SP/SR (e.g. completion of positive } \\
\text { data logs) }\end{array}$ \\
\hline Restorative & $\begin{array}{l}\text { Supervisor liaising with supervisee line manager and/or } \\
\text { arranging a three-way meeting }\end{array}$ \\
\hline $\begin{array}{l}\text { To ensure that as a person and as a worker one is not } \\
\text { left to carry, unnecessarily, difficulties, problems and } \\
\text { projections alone }\end{array}$ & Reviewing $\mathrm{BABCP}$ Codes of Conduct and Ethics together \\
\hline Normative/restorative & $\begin{array}{l}\text { Agenda-setting and prioritisation of supervision items/ } \\
\text { use of SP/SR strategies }\end{array}$ \\
\hline $\begin{array}{l}\text { To have space to explore and express personal distress, } \\
\text { restimulation, transference or countertransference that } \\
\text { may be brought up by the work }\end{array}$ & $\begin{array}{l}\text { Use of Moorey's Interpersonal Cycle worksheet to help } \\
\text { supervisee understand transference and } \\
\text { countertransference from a CBT perspective }\end{array}$ \\
\hline Normative/restorative & Supervisor draws on experience to provide suggestions \\
\hline $\begin{array}{l}\text { To plan and utilise personal and professional resources } \\
\text { better }\end{array}$ & for further reading or CPD activities \\
\hline Normative/restorative & Supervisor creates an environment that fosters ongoing \\
\hline To be proactive rather than reactive & $\begin{array}{l}\text { curiosity about the cognitive, emotional and } \\
\text { behavioural responses of each party; asks supervisee } \\
\text { to complete a supervision induction questionnaire } \\
\text { and/or Therapist Schema questionnaires to anticipate } \\
\text { problems that might arise in the therapeutic or } \\
\text { supervisory relationship }\end{array}$ \\
\hline Normative & Making reference to BABCP standards of conduct and \\
\hline To ensure quality of work & $\begin{array}{l}\text { minimum training standards; Roth and Pilling } \\
\text { competences; NICE guidelines }\end{array}$ \\
\hline
\end{tabular}

a theory of how supervisees learn and an instrument to test adherence to evidence-based supervision (Johnston and Milne, 2012; Milne, 2017).

Incorporating adult learning theory (e.g. Kolb, 1984) and through applying evidence-based principles to our understanding of supervision (Milne and Dunkerley, 2010; Milne and James, 2000), EBCS provides the most robust framework available for measuring supervisor competence (Milne, 2017). The supervision process is likened to supervisor and supervisee as two cyclists on a tandem bicycle with the front wheel representing the supervisor behaviours and the rear wheel capturing the experiential learning cycle (Milne and Dunkerley, 2010). Within EBCS, successful supervision can be identified through the supervisor taking the supervisee around the experiential learning cycle (acting, reflecting, conceptualising, experimenting and experiencing) during a supervision session. The Supervision Adherence and Guidance Evaluation (SAGE) is a tool that can be used to assess this process (the 'supervisee learning cycle'). It also measures the skills that are displayed by the supervisor (the 'supervison cycle') and a range of 'common factors' such as the ability to successfully relate to 
Table 2. Examples of sub-optimal forms of supervision

\begin{tabular}{cc}
\hline Common types of supervisory drift & Potential consequences \\
\hline $\begin{array}{c}\text { Omission of 'live' supervision (e.g. supervisor } \\
\text { does not listen to/watch any recordings of }\end{array}$ & $\begin{array}{c}\text { Supervisor only has the supervisee's account of clinical } \\
\text { practice therefore the opportunity to correct poor }\end{array}$ \\
the supervisee's clinical work) & practice is missed \\
Infrequent use of experiential methods & Supervisee 'procedural' knowledge remains limited, \\
(e.g. supervisor modelling, role play, & struggles to see issues from other perspectives \\
chair-work, self-practice of CBT) & (e.g. client) \\
No agenda/supervision question unclear & Supervisor and supervisee do not know if question has \\
& been answered/poor time management/supervisee \\
may feel that needs have not been met & Supervision does not fulfil its primary purposes of \\
supervision is used as a means for the & monitoring ethical practice and educating the \\
supervisee venting about personal or & supervisee to achieve or maintain competence/ \\
workplace issues & adherence \\
\hline
\end{tabular}

the supervisee, collaborate with them on agreed goals and effectively manage the session. It has been shown to have good content and construct validity (Milne et al., 2011).

\section{Potential characteristics of drift \\ Utilising SAGE}

SAGE appears to be the only recognised tool for measuring CBT supervisor skill and therefore is a highly valuable facet of CBT supervision and more specifically in detecting signs of drift. Using the Dreyfus scale and Likert ratings similar to the CTS-R (Blackburn et al., 2001) it is used to measure the presence or absence of a range of supervisor and supervisee behaviours as featured in the tandem model (Milne and Dunkerley, 2010) and as with the CTS-R, a cut-off score is given to indicate a minimal degree of supervisor competence. The SAGE can be used during Supervision of Supervision (SoS) to watch a video recording of a supervision session and mark the supervisor against the different criteria. It could also be used as a self-supervision activity where a supervisor may watch or listen to a recording of their own supervision session where they mark their performance formally or informally. Examples of where a supervision session indicates signs of drift using SAGE include a failure to demonstrate adequate teamwork with the supervisee (the 'common factors'), little evidence of focusing the supervisee by setting an agenda (the 'supervision cycle') and an absence of the supervisee reflecting on what they have learned during the session (the supervisee cycle) (Milne and Reiser, 2014).

\section{How prevalent is supervisory drift?}

Having established a benchmark for high quality, effective supervision and a reliable means of measuring supervisor competence, we can consider that sub-optimal forms of supervision will be defined as those practices where experiential methods are avoided or deprioritised and form the basis of supervisory drift (Milne, 2017; Pugh and Margetts, 2020). Sub-optimal supervision can then be categorised as either ineffective (e.g. does not deliver on intended outcomes such as supervisee skill development) or harmful (e.g. there is a clear detrimental effect on the supervisee's confidence or skill development) (Ladany et al., 2013). Table 2 provides examples of sub-optimal forms of supervision that may indicate supervisory drift in practice and the potential consequences that may stem from this. 


\section{Ineffective or harmful supervision}

Whilst drift and harm are not one and the same, it could be argued that they sit along a continuum of ineffective forms of supervision. Large scale surveys of supervisory practice are rare (e.g. Milne, 2016; Townend et al., 2002), therefore the current prevalence of ineffective supervision is difficult to determine although recent research suggests that avoidance of 'live' supervision (e.g. audio or video recordings) continues to be an issue (Roscoe et al., 2019). Collusion between supervisor and supervisee to avoid mutually undesirable aspects of supervision such as viewing oneself on video may prevent crucial learning from occurring (Milne et al., 2009).

Conversely, a number of supervision experts have written about the implications of poor supervision where harm may arise to the supervisee or their clients (e.g. Ladany et al., 2013; Milne, 2020). Harmful supervision per se is not the focus of this paper and therefore readers are directed to the recent work of Milne for a more thorough grounding.

\section{Behaviours associated with the best and worst supervisors}

In a study involving 128 participants, Ladany and colleagues (2013) identified behaviours that were suggestive of the best and worst supervisors. Supervisors that were highly rated by supervisees demonstrated high self-disclosure, interpersonal sensitivity and an agreement on the tasks of supervision, all of which resulted in a strong emotional bond. In contrast, the worst supervisors were perceived to lack technical and interpersonal skills, rarely utilised video or audio observation, and were punitive in their feedback to supervisees, all of which resulted in a weak supervisory alliance. Whilst not specific to CBT, it is likely that similar processes occur in all supervisory relationships (Watkins, 2020). Even if this does not amount to harm, 'supervisees may be at risk of receiving supervision which is at best banal and at worst less effective than it could be' (Pugh and Margetts, 2020).

\section{Section 2: Potential reasons for drift arising}

\section{The challenges in mandating specific supervision components}

Whilst supervision is often highly rated by practitioners (Townend et al., 2002; Weck et al., 2017) and championed as being an essential activity by both organisations providing CBT (e.g. National Health Service) and leading figures within CBT (e.g. Padesky, 2006) the evidence base to support the proposed outcomes remains fairly weak (Alfonsson et al., 2017; Grey et al., 2014). Roth and Pilling (2008) state 'the purpose of supervision should be to enhance client outcomes, but detecting a causal link is challenging, requiring that there is evidence that supervision impacts in some way on the supervisee, that this is translated into a change in their behaviours as therapists, and that this change improves outcomes' (p. 5).

\section{Client outcomes - the holy grail of supervision}

A troublesome question for those that wish to determine good versus bad supervision is whether there are any measurable consequences to supervision which is for example, overly restorative? Where supervisors, trainers, managers and accrediting bodies can hold a therapist to account for failing to adhere to or demonstrate competence in a particular evidence-based model or treatment (e.g. Ehlers and Clark, 2000) through the use of widely adopted measures such as the Cognitive Therapy Scale Revised (CTS-R) (Blackburn et al., 2001) or through a series of caseload reviews that indicate poor patient recovery, the same cannot be said for what should and should not be done in supervision. Research on supervisee satisfaction (Ladany et al., 2013), therapist skill development (Bennett-Levy, 2006) supervisee learning (James et al., 2006) and accrediting body regulations (e.g. BABCP) can loosely be used to define good quality supervision yet may be insufficient grounds to challenge a supervisor's practice on the grounds of incompetence. 
Furthermore, the degree to which expert developed manuals and instruments influence routine supervisory practice remains to be seen (Gyani et al., 2015; Milne, 2016). From the author's anecdotal experience, tools such as SAGE are not being applied routinely within supervision or Supervision of Supervision (SoS), which raises questions about the consistency and quality of CBT supervision.

\section{When and where is drift most likely to occur?}

Pugh and Margetts (2020) speculate that supervisory drift may occur due to limited supervisor knowledge (of supervision approaches including experiential methods), negative beliefs about these methods or their ability to utilise them, anxiety or shame around enactment, a desire to protect rather than risk the supervisory alliance through potentially challenging conversations and concerns about having the time to incorporate certain methods within a supervision session. This section seeks to expand on these ideas by hypothesising how a range of contextual, historical, intrapersonal and interpersonal factors may create the conditions under which supervisory drift develops. In addition to these reasons, the author proposes that a lack of familiarity with SAGE amongst CBT supervisors could be a significant factor, although further research is required to establish how widely it is used.

\section{Contextual factors}

The context in which supervision takes place might be an important factor to consider in the genesis and maintenance of drift. There is a dearth of research which captures how supervision is delivered and used outside of research trials (Roth et al., 2010). In randomised control trials (RCTs) supervision is often carried out by experts with considerable experience as clinicians and supervisors (Roth and Pilling, 2008). Supervision is usually weekly and supervisees are closely monitored for their adherence to treatment protocols (Turpin and Wheeler, 2011). In contrast, BABCP only require accredited therapists to receive 90 minutes per month, supervisors might be peers or of a similar level of experience to their supervisees and research on therapist drift suggests that adherence to protocols is variable (Townend et al., 2002; Sherman, 2021; Waller, 2009).

Furthermore, in routine clinical practice, service demands may lead to time pressures with an over-emphasis on the normative (case management) tasks at the expense of more reflective or experiential methods (e.g. Bennett-Levy and Thwaites, 2007; Pugh and Margetts, 2020; Scott, 2018). Conversely, private practice may allow for less intrusive forms of supervisions yet at the same time create the conditions for supervision that becomes too relaxed, lacking the essential hierarchical component (Milne, 2017).

During CBT training, the aims of supervision and the requirements of the supervisor and supervisee tend to be clear and rigorous. This reflects the demands of the training curriculum where training courses typically utilise competence measures such as the Cognitive Therapy Scale Revised (CTS-R) (Blackburn et al., 2001) and adhere to the BABCP minimum training standards (Liness et al., 2019). The challenge is that the role of supervision for qualified and experienced therapists is more open to interpretation owing to the fact that they may have less obvious formative or normative needs and there is less scrutiny than during training (Younge and Campbell, 2013). This opportunity for interpretation is frequently reported to be guided by the supervisor's own experience as a supervisee rather than any formal supervision guidelines (Townend et al., 2002; Milne, 2008; Younge and Campbell, 2013). Furthermore, this ambiguity might not be assisted by the absence of a unified model of supervisory practice (Armstrong and Freeston, 2006; Milne, 2008). 


\section{Potential contributing factors}

Pre-disposing factors - training and past experiences of supervision

It is hypothesised in this paper that both the supervisee and the supervisor enter the supervisory relationship with unique expectations of what supervision will entail and attitudes towards the ongoing purpose of supervision sessions. The format of supervision that one receives during their therapist training is likely to influence what one continues to expect from supervision in the future (Roscoe, 2021a). For example, a supervisee that receives supervision which incorporates a range of methods such as self-practice of CBT methods, role-play, modelling, video feedback and case discussion is likely to expect future supervisors to offer these formats. Conversely, the supervisee who has experienced restricted methods may not know what they are missing and therefore have low expectations from future supervisors.

\section{Supervisor cognitions}

Supervisors enter into the supervisory relationship as they do any other relationship with a set of beliefs about themselves and the world (as Bennett-Levy terms 'person-of-the-therapist', 2006) and a set of beliefs about therapy (the 'self-as-therapist' schema) derived from their clinical knowledge and skills that they have accrued in their therapeutic practice. It is hypothesised henceforth that the personal and therapist 'selves' influence a 'supervisor self (Corrie and Lane, 2015) which is derived from experiences of supervision (including but not limited to any supervisor training that has been attended, how they were and are supervised and the culture of supervision within the contexts in which they are employed).

It is not yet known which cognitions are specifically linked to supervisory drift (personal self, therapist self or supervisor self); however, there are likely to be parallels with those associated with therapist drift. For example, it has been suggested that many therapists find exposure-based activities aversive (Meyer et al., 2014), and given that supervisors are usually practising therapists themselves, individual beliefs held by the supervisor may also influence the direction and content of supervision, resulting at times in collusion with the supervisee to avoid mutually aversive aspects of treatment (Milne et al., 2009). It has also been theorised that specific beliefs held by supervisors might influence the degree to which they retain fidelity towards evidence-based practice (EBP). For example, Simpson-Southward et al. (2018) found that when more diffuse cases of depression were brought to supervision the advice supervisors would give tended to drift from EBP.

Some supervisors may also feel uncomfortable with the normative functions of their role, for example raising concerns about safe, ethical or competent practice with their supervisees. This may reflect certain therapist schemas held by the supervisor, for example 'need for approval' (see Haarhoff, 2006; Leahy, 2001). Such is their need to be liked by the supervisee that they may place too much emphasis on the restorative aspect of supervision and deprioritise normative and formative tasks.

\section{Supervisee cognitions}

As supervisory drift may also be supervisee-led, it is useful to consider what types of problematic supervisee cognitions could influence their decisions within supervision. A range of 'personal self core beliefs may be activated within supervision (e.g. 'I'm stupid' in response to corrective feedback from a supervisor on their technical execution of an intervention such as a worry script),'therapist self rules and assumptions (e.g. 'I must always know what I am doing'/'If I show my supervisor my weaknesses in my practice then they will judge me harshly') and situation specific negative automatic thoughts (e.g. 'The supervisor will see how rubbish I am 
Table 3. Supervisor and supervisee gameplay adapted from Delano and Shah (2006)

\begin{tabular}{|c|c|}
\hline Supervisor games & Supervisee games \\
\hline $\begin{array}{l}\text { They won't let me - blames managers, other supervisors, } \\
\text { 'the system' for their decisions to protect themselves } \\
\text { from the emotions of the supervisee }\end{array}$ & $\begin{array}{l}\text { Protect me/treat me - using personal issues to } \\
\text { redirect possible scrutiny over role performance }\end{array}$ \\
\hline $\begin{array}{l}\text { I'm really one of you - trying to pledge allegiance to } \\
\text { the supervisee and deny power }\end{array}$ & $\begin{array}{l}\text { Evaluations are not for friends - trying to engage } \\
\text { the supervisor in a friendship relationship so as to } \\
\text { reduce the likelihood of criticism }\end{array}$ \\
\hline $\begin{array}{l}\text { Remember who's boss - no challenges are allowed to } \\
\text { their authority or knowledge }\end{array}$ & $\begin{array}{l}\text { Head it off at the pass - brings 'crisis' situations to } \\
\text { the agenda thereby diverting attention from their } \\
\text { clinical skills }\end{array}$ \\
\hline $\begin{array}{l}\text { I know you really can't do it without me - withholding } \\
\text { resources from the trainee to feel needed or fostering } \\
\text { dependence rather than gradual independence }\end{array}$ & $\begin{array}{l}\text { What you don't know won't hurt me - only bringing } \\
\text { certain cases as a means of hiding feelings of } \\
\text { incompetence from the supervisor }\end{array}$ \\
\hline
\end{tabular}

at agenda setting if I agree to doing role-play with them'). Beliefs such as 'The supervisor is always right' might prevent a supervisee from suggesting a variation to how supervison is structured (e.g. being reluctant to suggest that the supervisor include more modelling in sessions).

\section{Supervisor emotions}

Newly appointed supervisors may feel anxious about being seen as knowledgeable enough to perform in the role (Corrie and Lane, 2016). They might also feel embarrassment or shame in relation to their own clinical work if they perceive that the supervisee is likely to criticise their level of skill during a modelling or role play task.

\section{Supervisee emotions}

Supervision, whether group or one-to-one, involves the supervisee having to let others see and evaluate their clinical work. This is likely to trigger a range of emotions such as anxiety (anticipatory) fear (during the session), shame (believing that the supervisor or peers can see how bad they are), embarrassment (at being the centre of attention) and sadness (where ruminative self-critical thoughts may arise post-supervision). Failing to normalise and name these emotions within supervision could lead to supervisees engaging in a range of safetyseeking behaviours to protect themselves (see Milne et al., 2009).

\section{Supervision-interfering behaviours}

Just as therapist and client may knowingly or unknowingly engage in therapy-interfering behaviours (Waller, 2009), supervision dyads may hold within them a range of supervisioninterfering behaviours that are either supervisor-led, supervisee-led or a result of collusion between both parties (Milne et al., 2009). Kadushin (1968) proposed that supervisors and supervisees may engage in various 'games' within the supervision process, as highlighted in Table 3.

Described as 'recurrent interactional incidents between supervisor and supervisee that have a payoff for one of the parties in the transaction' (p. 55) these games are not necessarily in the immediate awareness of each party; however, their presence may lead to ineffective supervision or ruptures emerging when one party refuses to 'play'. Gameplay could be considered as a means of protecting either or both parties from difficult cognitions and emotions that may arise within supervision. 
To summarise, it is hypothesised that a range of pre-disposing factors including one's history of being supervised and the context in which supervision is delivered may give rise to a number of problematic supervisor and supervisee cognitions and emotions that are perpetuated through the use of gameplay within supervision. This may include attitudes towards the use of certain aspects of supervision such as role play, modelling or video feedback. Drift may arise or continue due to these cognitions, emotions and behaviours going unnoticed or unchallenged. The next section will provide examples of how supervisors, supervisees or meta-supervisors can identify signs of drift in routine practice.

\section{Section 3: Getting back on track in supervision using a bespoke formulation}

\section{Identifying drift in routine practice}

Recognising and responding to drift is the responsibility of all parties involved in supervision, therefore drift could be identified by the supervisee, supervisor, meta-supervisor or line manager. This could be recognising behaviours within oneself as a supervisee that indicate drift (e.g. only bringing questions rather than recordings to supervision), recognising the receipt or provision of restricted supervision methods through the formal or informal use of the SAGE (e.g. verbal case discussion every session). Once drift has been identified either through a discussion between supervisor and supervisee, through self-supervision or within supervision of supervision (SoS), it is necessary for there to be a means of making sense of why this has occurred, a benchmark for what supervision has strayed from (e.g. Tandem model, Gordon's ten steps, BABCP guidance) and how to get supervision back on track. Whilst macro-skills such as setting out a supervision contract at the start of the relationship is one way of determining if one or both parties have neglected their agree duties, it is the 'micro-skills' of the supervisor (James et al., 2008) that help to successfully manage this. Three hypothetical examples are presented below to illustrate where drift could be identified and how solutions might be explored and initiated.

\section{Case example 1}

Martin (supervisee) and Nigel (supervisor) both worked in an NHS service. Martin noticed that his supervision with Nigel felt rushed and that he tended to only receive advice from him when he was stuck with clinical cases. Martin had read the Gordon (2012) paper and wanted to have more chance to engage in role plays during supervision but had felt reluctant to bring this up with Nigel for fear of offending him or being punished. Their sessions would often drift off topic to become more restorative (e.g. mutual rants about service targets) with little focus on the normative and formative tasks. Furthermore, Nigel did not ask Martin to bring recordings to supervision, so he only had the word of his supervisee that he was practising competently. It could therefore be argued that in this supervision dyad there was a lack of agreement on the tasks of supervision (Ladany et al., 2013). In a SoS session, Nigel's meta-supervisor, Lisa, asked him to bring a recording of a supervision session to jointly review his practice. When they watched the footage, Lisa applied the SAGE rating scale (Milne et al., 2011) and noticed several missed opportunities where Nigel could have taken a more experiential approach with Martin. Using Socratic dialogue Lisa asked Nigel about what he noticed about the session content and structure. Watching the session back allowed Nigel to 'reflect-on-action' (Schön, 1987) and he immediately realised that the session felt more like a 'chat', lacked clear supervision questions on the part of the supervisee and there was an absence of 'active' methods such video review, modelling or role play. Using Kolb's (1984) learning cycle, Lisa checked if Nigel had the knowledge and skills to make changes to his supervisory practice based on what they had 
identified. Nigel possessed the declarative knowledge about how to do modelling and role play but lacked confidence in the procedural application of these methods. Lisa modelled these methods and then asked Nigel to swap roles and to model introducing role play. Following this, Nigel developed a plan for addressing the loose structure to his supervision sessions including a review of Martin's bespoke needs. Furthermore, Nigel aimed to vary how he responded to supervisees by modelling rather than simply telling them what to do.

\section{Case example 2}

Maureen and Pat were both working in private practice and had been engaged exclusively in a peer supervision arrangement for the last 18 months. Ian had asked to join them and immediately noticed significant differences from the supervision he had experienced prior to this. Whilst Ian welcomed a greater sense of autonomy compared with what he felt was micromanagement previously, he was concerned that there was no one 'in charge' to oversee structure to the peer supervision group. There was no agenda set at the start of the sessions and from what Ian had observed, it appeared as if Maureen and Pat used the time to predominantly 'offload' about their clients. No constructive criticism was provided by either party, which led to Ian feeling awkward about sharing feedback with Maureen or Pat. Having recently attended some supervisor training, Ian recognised that Maureen and Pat appeared to be caught up in the game 'Evaluations are not for friends' (Delano and Shah, 2006; Kadushin, 1968). Reflecting on how this might lead to ineffective supervision at times, Ian suggested that one person take the lead each session, rotating between the three of them. This would ensure that a clear agenda was set and there would be a reminder of times being allocated to each supervisee to discuss items. Ian also suggested that they review the SAGE document at their next meeting to see how this could be used to inform the quality of their supervision experience. Maureen and Pat initially held some reservations but agreed to try this new format going forward.

\section{Case example 3}

Alicia would often come to supervision unprepared and proceed to give her supervisor Waseem lots of details about the client's history, often meaning that they were unable to finish the session with a clear understanding of what she was going to do differently based on supervision. Furthermore, Waseem was often unsure what Alicia's declarative knowledge or procedural understanding were of various problems due to having insufficient time to review this. When asked to generate some specific supervision questions by Waseem, Alicia would become defensive, stating that she did not have sufficient time to prepare questions in advance. Alicia would also accuse Waseem of being too 'business like' when he tried to set a clear agenda. Waseem was concerned that if he continued to push Alicia to be more structured, this would strain their relationship and cause a rupture.

\section{Formulating the problem}

Relating these three vignettes to Pugh and Margetts' (2020) definition of drift, various aspects of supervision had been unintentionally 'omitted, avoided or deprioritised' (p. 5). Martin's unspoken needs, Nigel's lack of confidence, Alicia's inefficiency and Maureen and Pat's dislike of too much structure and discomfort with giving each other critical feedback had inadvertently led to supervision that was potentially lacking in at least one aspect of the primary functions (normative, formative, restorative). Without a CBT specific means of raising this, for Martin, 
Ian and Waseem as supervisors or for Lisa as a meta-supervisor, highlighting these concerns could potentially lead to defensiveness from the other parties or at worst a rupture (Haarhoff, 2006).

How then can a supervisor, supervisee or meta-supervisor bring these issues to light in a way that fosters curiosity and collaboration rather than defensiveness? Given that in many respects, the exchanges occurring within supervision are more complex than those occurring within therapy' (James et al., 2008; p. 29), consideration is needed around how and when to raise concerns within the supervision dyad. A tool already familiar to CBT practitioners, formulation is one such means of developing a shared understanding of potentially problematic behaviour such as drift. A cognitive conceptualisation of within-supervision behaviours should assist the supervisor and supervisee or meta-supervisor and supervisee evaluee (Newman, 2013) in 'de-centring' from their typical dynamic (i.e. to take a step back from habitual behaviours such as the supervisee venting about their employer and the supervisor passively allowing this).

It should also provide a shared language for the dyad to discuss problematic behaviours in a curious and non-confrontational way. To do so, it should draw upon existing CBT formulations and terminology so that it is accessible for the supervisor to draw out with the supervisee during a supervision session. The information that is captured in the formulation might start with a simple five areas model (see Wright et al., 2002) and progress to an interpersonal or longitudinal version including relevant background information should the need arise. Both versions would include the cognitions, emotions, physiology and behaviours of one or both parties, together with an appreciation of their respective learning histories.

The formulation presented below in Fig. 1 is one of way of conceptualising supervisory drift and is a modified version of Moorey's (2013) Interpersonal Cycle worksheet to illustrate how supervisory drift may arise. Past experiences and contextual factors are added to help both parties make sense of the reasons why they have developed specific beliefs and behaviours within supervision. Using Nigel and Martin as an example, it demonstrates how Lisa drew out the problem behaviour during a SoS session. Longitudinal information such as 'personal self information about the supervisor or supervisee might not be known by the person drawing out the model and, in this case, Lisa worked with what she knew of Nigel's therapist and supervisor 'selves' and his knowledge of Martin's history. The formulation helped Nigel to understand that he needed to know more about what Martin was experiencing within supervision (his cognitions and emotions about supervision) and how his previous experiences of supervision might be influencing how he behaves with Nigel.

\section{Section 4: Potential solutions}

\section{Staying on track}

Avoiding drift at the outset is preferable; however, all supervisors and supervisees are only human and therefore susceptible to making mistakes. As Waller (2009) aptly puts it, 'errors are unavoidable and to be expected. The key is whether we spot them and respond to them appropriately' (p. 121). Having a clear idea of where one needs to be is a useful starting point and therefore becoming familiar with best practice guidance and becoming familiar with SAGE and regularly using it within supervision, SoS or self-supervision is essential (see Armstrong and Freeston, 2006; Bennett-Levy and Thwaites, 2007; Corrie and Lane, 2015; Cummings et al., 2015; Gordon 2012; James et al., 2006; Milne et al., 2011; Pretorius, 2006) is recommended. From the author's prior research and experience as a trainer of supervisors, not all who practise do so with knowledge of SAGE or these best practice principles (Roscoe et al., 2019). The availability and content of supervisor training and the importance that employers place on ensuring their supervisors have access to it could be crucial to this (Culloty et al., 2010; Younge and Campbell, 2013). 


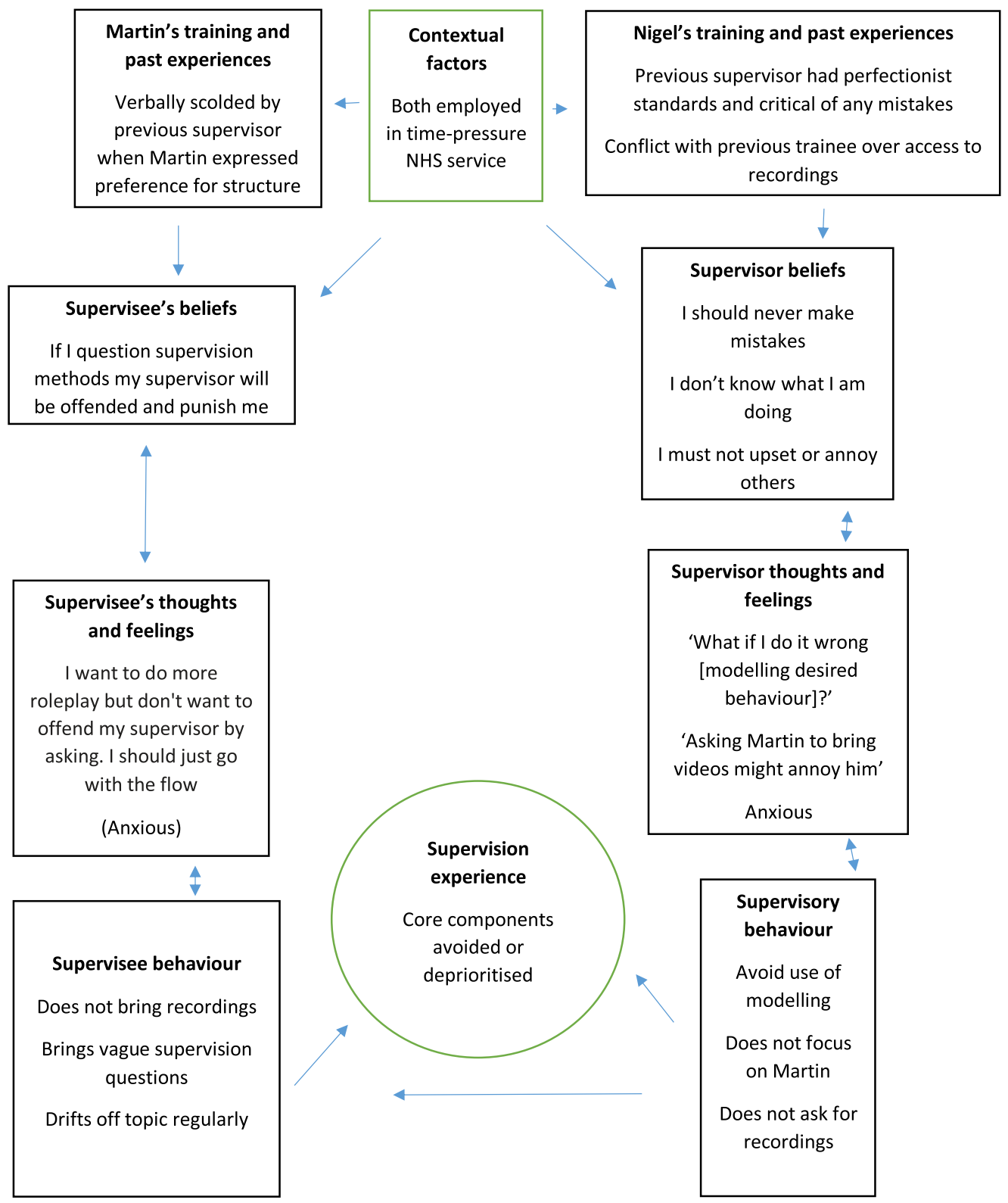

Figure 1. Supervisory drift formulation (based on Moorey, 2013) used in Supervision of Supervision (SoS) to help supervisor-evaluee Nigel make sense of his restrictive use of supervision methods.

Furthermore, as previously stated, supervision is not yet at a stage where a specific protocol can be mandated in the way that evidence-based protocols for CBT treatment are. In the absence of this, effective CBT supervision is guided by the combination of an emerging evidence base (Milne, 2017), expert recommendations (e.g. Pretorius, 2006) and accrediting body standards (e.g. BABCP). By having these principles in mind, supervision dyads can jointly reflect on whether supervision sessions have included these facets on a regular basis.

Formulation might capture different types of games that supervisor or supervisee have been playing. For supervisors, SoS would appear to be the most obvious setting to review 
Table 4. Ways to reduce likelihood of drift

\begin{tabular}{|c|c|}
\hline Recommendations for supervisees & Recommendations for supervisors and meta-supervisors \\
\hline $\begin{array}{l}\text { Develop specific supervision questions so that } \\
\text { you know exactly what you want to get } \\
\text { from each session }\end{array}$ & $\begin{array}{l}\text { Consider using supervision satisfaction measures with your } \\
\text { supervisees, e.g. Leeds Alliance in Supervision Scale } \\
\text { (Wainwright, 2010) }\end{array}$ \\
\hline $\begin{array}{l}\text { Read the Roth and Pilling supervisor } \\
\text { competences (2008) and/or Gordon (2012) } \\
\text { so that you have a set of standards to look } \\
\text { for in your supervisor }\end{array}$ & $\begin{array}{l}\text { Consider using SAGE (Milne and Reiser, 2014) as a means of } \\
\text { structuring SoS sessions and setting } \\
\text { discrete behaviours to work on with the supervisor-evaluee }\end{array}$ \\
\hline $\begin{array}{l}\text { Consider applying CBT methods to your own } \\
\text { negative automatic thoughts about your } \\
\text { skills as a therapist and/or your supervisor }\end{array}$ & $\begin{array}{l}\text { Consider using a supervision contract at the start of the } \\
\text { supervisory relationship and a supervision induction } \\
\text { questionnaire (e.g. Clohessy, 2019) to establish supervisee } \\
\text { learning styles and key background information }\end{array}$ \\
\hline \multirow{4}{*}{$\begin{array}{l}\text { Check with your supervisor if they have } \\
\text { attended specific supervisor training, if they } \\
\text { are accredited as a supervisor and what } \\
\text { they perceive to be their strengths and } \\
\text { weaknesses }\end{array}$} & $\begin{array}{l}\text { Consider attending 'top up' supervisor training or } \\
\text { readings books or papers on managing interpersonal } \\
\text { processes in supervision }\end{array}$ \\
\hline & $\begin{array}{l}\text { Read the Gordon (2012) and Pretorius (2006) papers for further } \\
\text { guidance on best practice }\end{array}$ \\
\hline & $\begin{array}{l}\text { Consider incorporating self-practice/self-reflection practices } \\
\text { within supervision (e.g. asking supervisee to identify their own } \\
\text { negative automatic thoughts about the supervisor, complete } \\
\text { the Therapist Schema Questionnaire together (Leahy, 2001) }\end{array}$ \\
\hline & $\begin{array}{l}\text { Seek to engage in Supervision of Supervision to help one to } \\
\text { 'de-centre' from relationships with supervisees }\end{array}$ \\
\hline
\end{tabular}

supervision structure and content. Using the Milne and Dunkerley tandem analogy (2010), reviewing the supervisory dynamic could be seen as both cyclists 'pulling over' to rest, review where they have been so far and where they are heading. Potential or actual indicators of drift can then be discussed and problem solved.

\section{Anticipating problems before they arise}

To normalise interpersonal and intrapersonal reflection within supervision it can be helpful to gather a basic overview of the supervisee's personal self and therapist self history, in order to construct a 'psychological contract' (Clohessy, 2019). Using either a written questionnaire or a pre-supervision interview, the supervisor can ascertain important aspects of how to manage the supervisory relationship by asking the supervisee questions such as 'what background information (either personal or therapist self' do you think it is important for me to know about you?' or 'how might we address differences of opinion?'. Supervisor and supervisee can then use the responses to these questions to anticipate instances in supervision where these might be relevant. This might involve mapping out some of the boxes in Fig. 1 and building a written formulation up over several supervision sessions. For example, if Nigel had asked Martin to complete an induction questionnaire, then he could have established his learning preferences and past experiences of supervision earlier in their supervisory relationship. Similarly, if Waseem had completed this with Alicia, they would have recognised from the beginning that they have very different styles and could have planned for how they might work together to reach a compromise.

\section{Recommendations}

Table 4 provides a range of suggestions for ways in which supervisors and meta-supervisors can introduce a range of safeguards to minimise the risk of supervisory drift. Similarly, supervisees 
would benefit from knowing how to be an effective supervisee (Bliss et al., 2018) and a summary of recommendations for both members of the dyad are provided below, which might reduce the likelihood of drift occurring if these are in place.

\section{Adapting supervision to the needs of the supervisee}

It could be argued that a competent supervisor will not only move between normative, formative and restorative tasks based on the emotional and learning needs of the supervisee, but also consider the learning style preferences and context in which the supervision takes place (Grey et al., 2014; James et al., 2006). For example, qualified therapists may have fewer formative needs than trainees having grasped the basics of formulation and disorder specific treatment and therefore supervision may require a greater focus on the normative (e.g. addressing ethical challenges), or restorative aspects (where the supervisee needs to emotionally process a challenging therapy session with a hostile client). Conversely, inexperienced therapists may require a greater formative focus (e.g. teaching the supervisee an intervention through modelling or role play). Furthermore, the Declarative-Procedural-Reflective (DPR) model of therapist skill development and refinement by Bennett-Levy (2006) can usefully inform the educative functions of supervision. Whilst a detailed explanation of this model is beyond the scope of this paper, in summary, supervisors might gauge the declarative knowledge of their supervisees (e.g. by asking what they know about the diagnostic criteria for a given disorder, what the model and interventions are and in what order) and also the procedural knowledge (e.g. how often the supervisee has put into practice their declarative knowledge by applying these interventions with clients). In doing so, supervisors can try to tailor supervision to the stage of development of their supervisee (Pretorius, 2006).

\section{Using active supervision methods to better understand drift}

Drawing on the concept of 'self-multiplicity' (Pugh, 2019a), supervisors can bring to life the different selves of the supervisee (the personal self, therapist self and supervisee self) and their relative contributions to supervision (Bennett-Levy, 2006; Pugh, 2019a; Pugh 2019b; Pugh and Margetts, 2020). Utilising the examples and format of in-person or online cognitive behavioural chair work (Pugh, 2019a; Pugh and Bell, 2020), the supervisor might ask the supervisee to embody the three 'selves' at different points during a supervision session using 'intrapersonal role-plays' (Pugh, 2019b; p. 5) with the aim of developing meta-cognitive awareness of the motivations that belong to each 'self. For example, the supervisor might suggest interviewing the part of the supervisee that is resistant to certain aspects of supervision (e.g. showing recordings of therapy sessions). The supervisee intake questionnaire might be a useful document to refer to when setting up this exercise. See Fig. 2 for a fictional example of this method in action.

In the above vignette, the supervisor clearly links the rationale for the exercise to a potential difficulty that was flagged up at the start of the supervision contract (handling any form of criticism). The supervisor then proceeds to interview the supervisee's 'personal self who as it transpires is very sensitive to any perceived criticism and tends to personalise and ruminate on negative feedback. Following this, they also interviewed the supervisee's therapist self (by switching chairs to embody the other part of them) who was able to put forward several useful reasons for making video feedback a more integral part of supervision. The supervisor concluded the chair work by asking the supervisee to open a dialogue between personal and therapist selves by getting the supervisee to move back and forth between different chairs. Adding a playfulness to supervision potentially reduces the likelihood of conflict between supervisor and supervisor, instead allowing them both to team up to better understand normal processes that can get in the way. The supervisor could help to normalise this by 
Supervisor: I've noticed that you don't tend to bring many recordings of your sessions to supervision, is that something that you are a ware of too?

Supervisee: / guess so.

Supervisor: Okay, l'd be curious to explore this with you today particularly as we had noted in your pre-supervision questionnaire when we first started working together that perceived criticism is something you have struggled with in the past. On that basis would you be willing to try an exercise that I had in mind?

Supervisee: Sure, we can give it a go. What does it involve?

Supervisor: Well, it might seem a little odd or silly but l'd like to speak to the part of you that really hates showing videos. We all are in two minds about many things, losing weight, quitting smoking, etc. There might be a part of you that wants to show vide os but also a part of you that dislikes this and tries to a void it all at costs.

Supervisee: Yeah does sound a bit weird but let's give it a try.

Figure 2. Using chair work to identify factors involved in drift.

modelling what their own resistant self thinks about bringing videos to supervision. Finally, completing the Therapist Schema Questionnaire (Haarhoff, 2006; Leahy, 2001) during supervision could be another way to normalise problematic beliefs and behaviours that both supervisor and supervisee could be vulnerable to. Recent research suggests that CBT trainees may be receptive to learning about interpersonal and intrapersonal processes and bringing related to questions to supervision (Roscoe, 2021a), therefore incorporating this within standard CBT training could assist in self-reflective skills.

\section{Supervision of Supervision}

Similarly in SoS, the meta-supervisor facilitates a process of reflection to allow the supervisorevaluee to consider how their various selves contribute to their supervisory practice. As demonstrated in the earlier vignette with Nigel, supervisors may struggle to be objective about their supervisory competence or blind spots. For this reason, engaging in SoS is essential for developing and improving the capacity to 'de-centre' from supervision (Barton, 2015). A fresh set of eyes allows an impartial observation of the dynamics that are in operation between supervisor and supervisee. The meta-supervisor can also use recognised frameworks on which to offer feedback on the supervisor-evaluee skillset (see Gordon, 2012; Milne and Reiser, 2014). There has been little written on SoS (as an exemplar, see Newman, 2013) to guide those who might provide it or look to access it. From the author's experience, manuals such as SAGE (Milne et al., 2011; Milne and Reiser, 2014) provide a benchmark for the formal marking of supervision sessions against a recognised set of criteria. A significant benefit of SAGE is that due to it using the Dreyfus scale, those already familiar with the CTS-R (Blackburn et al., 2001) are likely to be able to adapt to it reasonably quickly. By reviewing video or audio footage with a meta-supervisor or as a self-supervision exercise (Bennett-Levy and Thwaites, 2007), SAGE scores 18 supervisor behaviours and five supervisee behaviours, and this might assist the supervisor in recognising patterns in how they behave during supervision sessions (e.g. a tendency to collude with avoidant supervisees). 


\section{Alliance measures}

A strong supervisory relationship has been shown to predict our current understanding of what constitutes successful or highly effective supervision (Moorey and Byrne, 2019). Frequently measuring how strong the alliance is would seem sensible; however, it is difficult to establish from the existing literature how widely used alliance measures are within routine CBT supervision. Capturing the supervisee's overall satisfaction with supervision using a validated measure may facilitate the disclosure of helpful negative feedback which might otherwise not be volunteered (Ladany et al., 2013; Yourman, 2003). A measure triggers a discussion of the feedback and may provide a useful opportunity for a mutual exchange of feedback about each party's experience of supervision. If Nigel had used an alliance measure with Martin, then the dissatisfaction with supervision structure could have been detected earlier. Whilst there is no widely endorsed CBT-specific alliance measure for supervision, the Leeds Alliance in Supervision Scale (Wainwright, 2010) is an example of a measure that is brief enough to be administered at the end of a supervision session and can be reviewed as part of the next session agenda. Specific scales designed to elicit therapist cognitions which relate to drift have been proposed (Rameswari et al., 2021) and referring supervisees to literature such as this and other related concepts (e.g. Leahy's Therapist Schemas) may help to normalise discussion of therapy-interfering beliefs and behaviours within supervision (Leahy, 2001; Moorey and Byrne, 2019).

\section{Discussion}

The aim of this paper was twofold. Firstly, it aimed to draw together the minimal existing knowledge about the identification and management of supervisory drift within CBT. This involved a review of the extant literature on the functions of supervision, the state of play in supervision research and extracting potentially relevant concepts from neighbouring literature (e.g. therapist schemas, skill development and drift). As a result, this is the first CBT-specific paper to propose a set of pre-disposing factors that seek to explain the origins and maintenance of supervisory drift.

Secondly, it aimed to be a practical resource for supervisors and supervisees to relate to their supervisory practice by reflecting on their use of supervision and the reasons for this. Examples of where drift might be occurring have been provided, together with a summary of best practice recommendations that might reduce the possibility of drift occurring. It is hypothesised that drift is often an unintentional process, characterised by a lack of emphasis on the formative and normative aspects of supervision arising from a combination of supervision context, supervisor and supervisee beliefs, emotions and safety-seeking behaviours.

\section{Future directions}

The hypothesised causes of supervisory drift presented in this paper lack empirical data at present and consist of existing ideas about therapist skill development (Bennett-Levy, 2006), supervision research and interpersonal processes (Haarhoff, 2006; Kadushin, 1968; Moorey and Byrne, 2019; Thwaites and Bennett-Levy, 2007; Roscoe, 2021b; Watkins, 2020). Further research is required to test both the components of the model (e.g. the presence of specific maladaptive supervisor and supervisee cognitions) and the face validity and acceptability of this amongst practising supervisors.

The refinement of the model will require input from supervisors and supervisees through presenting it in supervisor training workshops, focus groups or questionnaire-based feedback on the strengths and weaknesses of the model. A lack of familiarity with therapist schemas by 
supervisors could be a barrier to the immediate accessibility of the model and therefore consideration is needed in terms of how much training will be needed. It would also be necessary to establish the most appropriate platform for its use (e.g. within a standard supervision review or within SoS).

Many questions remain unanswered therefore, and to better understand supervisory drift (SD) more generally it is necessary to answer several questions that we still know little about, including but not limited to, the following:

- When is SD most likely to occur in a supervisee's career? (e.g. in training or when one has been qualified for over 10 years)

- Is SD more likely in novice or highly experienced supervisors?

- Are certain supervision formats more susceptible to SD than others? (e.g. webchat/peer supervision)

- Is there a relationship between engaging in supervisor training and being less likely to drift as a supervisor?

- Is there a measurable relationship between certain therapist schemas (e.g. need for approval) and SD?

- Does SD negatively impact the quality of therapy delivered in clinical practice by the supervisee?

- Does supervision of supervision and the use of related tools (e.g. SAGE) reduce the frequency of drift?

Suspicions of drift should always be raised gently and without jumping to conclusions. Returning to Pugh and Margetts' (2020) definition of drift where core components are 'omitted, avoided or deprioritised', what might appear to be drift, could be highly responsive supervision that is tailored to the needs of the individual at a particular moment in time rather a rejection of the manuals. The SAGE, for example, allows for the marker to omit certain criteria if they are not deemed applicable to the needs of the supervisee in any given session (Milne, 2017).

Moreover, as Kennerley et al. (2017) caution, 'embarrassingly for an approach that values empiricism as CBT does, there is not yet a significant body of evidence about whether CBT supervision actually makes a difference, either to the supervisee's skills or to the outcomes for clients' (p. 428). In other words, for supervisory drift to be considered a serious problem that requires addressing, there needs to be tangible 'real world' consequences to poor supervision. Whilst it is relatively easy to see the consequences of therapist drift (e.g. therapist delivers incorrect or ineffective treatment to a client who then fails to recover from their episode of depression or anxiety disorder), the measurable effects of supervisory drift are arguably more difficult to establish.

Furthermore, drift does not necessarily equate to harmful supervision for the supervisee (for a description of unethical and harmful experiences in supervision, see Reiser and Milne, 2016). In the supervision vignettes that were used earlier it could be speculated that the absence of a set of basic over-arching principles (e.g. Pretorius, 2006) made it more likely for drift to arise. In light of this and to work effectively with the array of challenges that can emerge in the supervisory relationship, a range of supervisor 'micro-skills' are required to identify, formulate and work through drift when it arises. SAGE offers a validated tool to supervisors to self-reflect on their own work or for meta-supervisors to work within an evidence-based framework when giving feedback on supervisor skill. Finally, humility and curiosity rather than an authoritarian and 
judgemental approach are key interpersonal pre-requisites for supervisors and meta-supervisors when raising this topic.

Key practice points

(1) CBT supervisors and meta-supervisors can draw upon existing CBT principles including self-practice and selfreflection (e.g. Bennett-Levy et al., 2001; Haarhoff, 2006) to help supervisees make sense of supervisory drift and why it occurs.

(2) A bespoke formulation of supervisory drift enables the supervisor and supervisee to have a shared language for examining drift with curiosity rather than criticism and defensiveness.

(3) There is an EBCS framework and range of existing best practice resources that meta-supervisors can draw upon to assist less experienced supervisors in evaluating and improving their skills and self-reflection (e.g. Gordon, 2012; Milne, 2017; Milne and Reiser, 2014) and which supervisors can introduce to their supervisees to promote more effective use of supervision time (e.g. Grey et al., 2014; Kennerley et al., 2017; Padesky, 1996).

(4) Further research is needed to test the acceptability of the proposed model in routine practice by supervisors, meta-supervisors and supervisees.

Acknowledgements. The author is grateful to Julie Taylor, Rhiannon Blackley and Mathew Pugh for general support with preparing this paper, and the supervisors who have attended supervision training and contributed to discussions which led to the development and refinement of several ideas within the paper.

Financial support. The author received no funding for this piece of research.

Conflict of interests. The author has no conflict of interests with respect to this paper.

Ethics statements. The author has abided by the Ethical Principles of Psychologists and Code of Conduct as set out by the BABCP and BPS. Ethical approval was granted by University of Cumbria (reference number 17/59).

Data availability statement. Data availability is not applicable to this article, as no new data were created or analysed in this study.

Author contribution. As sole author, Jason Roscoe takes full responsibility for all aspects of this paper.

\section{Further reading}

Haarhoff, B. A. (2006). The importance of identifying and understanding therapist schema in cognitive therapy training and supervision. New Zealand Journal of Psychology, 33, 126-131.

Milne, D. L., Leck, C., \& Choudhri, N. Z. (2009). Collusion in clinical supervision: literature review and case study in self-reflection. Cognitive Behaviour Therapist, 2.

Pugh, M., \& Margetts, A. (2020). Are you sitting (un) comfortably? Action-based supervision and supervisory drift. The Cognitive Behaviour Therapist, 13, e17.

\section{References}

Alfonsson, S., Spännargård, Å., Parling, T., Andersson, G., \& Lundgren, T. (2017). The effects of clinical supervision on supervisees and patients in cognitive-behavioral therapy: a study protocol for a systematic review. Systematic Reviews, 6, 1-6.

Armstrong, P. V., \& Freeston, M. H. (2006). Conceptualising and formulating cognitive therapy supervision. In Tarrier, N. (ed), Case Formulation in Cognitive Behaviour Therapy, pp. 349-371. Routledge/Taylor \& Francis Group.

Barton, S. (2015). Supervisory supervision - conceptual model and practical guidance. BABCP Annual Conference, 24 July 2015.

Beck, J. S., \& Beck, A. T. (1995). Cognitive therapy: Basics and beyond (No. Sirsi) i9780898628470). New York: Guilford press.

Bennett-Levy, J. (2006). Therapist skills: a cognitive model of their acquisition and refinement. Behavioural and Cognitive Psychotherapy, 34, 57-78. 
Bennett-Levy, J. \& Thwaites, R. (2007). Self and self-reflection in the therapeutic relationship: a conceptual map and practical strategies for the training, supervision and self-supervision of interpersonal skills. In Gilbert, P., \& Leahy, R. L. (eds), The Therapeutic Relationship in the Cognitive Behavioral Psychotherapies. Routledge.

Bennett-Levy, J., Turner, F., Beaty, T., Smith, M., Paterson, B., \& Farmer, S. (2001). The value of self-practice of cognitive therapy techniques and self-reflection in the training of cognitive therapists. Behavioural and Cognitive Psychotherapy, 29(2), 203-220.

Blackburn, I. M., James, I. A., Milne, D. L., Baker, C., Standart, S., Garland, A., \& Reichelt, F. K. (2001). The Revised Cognitive Therapy Scale (CTS-R): psychometric properties. Behavioural and Cognitive Psychotherapy, $29,431$.

Bliss, P., Convery, D., Kellet, S., \& Spark, M. (2018). Being an Effective Supervisee. BABCP Annual Conference Skills Class, Glasgow.

Clohessy, S. (2019). The supervisory relationship and contracting. Oxford Cognitive Therapy Centre, CPD Event, 25 November 2019.

Corrie, S., \& Lane, D. A. (2015). CBT Supervision. Sage.

Corrie, S., \& Lane, D. A. (2016). Supporting the supervisor: organizing professional development to enhance practice. The Cognitive Behaviour Therapist, 9.

Culloty, T., Milne, D. L., \& Sheikh, A. I. (2010). Evaluating the training of clinical supervisors: a pilot study using the fidelity framework. The Cognitive Behaviour Therapist, 3, 132-144.

Cummings, J. A., Ballantyne, E. C., \& Scallion, L. M. (2015). Essential processes for cognitive behavioral clinical supervision: agenda setting, problem-solving, and formative feedback. Psychotherapy, 52, 158.

Delano, F., \& Shah, J. (2006). Professionally packaging your power in the supervisory relationship. Scottish Journal of Residential Child Care, 5, 34.

Ehlers, A., \& Clark, D. M. (2000). A cognitive model of posttraumatic stress disorder. Behaviour Research and Therapy, 38, 319-345.

Gordon, P. K. (2012). Ten steps to cognitive behavioural supervision. Cognitive Behaviour Therapist, 5.

Grey, N., Deale, A., Byrne, S., \& Liness, S. (2014). Making CBT supervision more effective. In Whittingham, A., \& Grey, N. (eds), How to Become a More Effective CBT Therapist: Mastering Metacompetence in Clinical Practice. Wiley \& Sons.

Gyani, A., Shafran, R., Rose, S., \& Lee, M. J. (2015). A qualitative investigation of therapists' attitudes towards research: horses for courses? Behavioural and Cognitive Psychotherapy, 43, 436.

Haarhoff, B. A. (2006). The importance of identifying and understanding therapist schema in cognitive therapy training and supervision. New Zealand Journal of Psychology, 33, 126-131.

Hawkins, P., \& Shohet, R. (2000). Supervision in the Helping Professions. Open University Press.

James, I., Milne, D., Marie-Blackburn, I., \& Armstrong, P. (2006). Conducting successful supervision: novel elements towards an integrative approach. Behavioural and Cognitive Psychotherapy, 35, 191-200.

James, I. A., Milne, D., \& Morse, R. (2008). Microskills of clinical supervision: scaffolding skills. Journal of Cognitive Psychotherapy, 22, 29.

Johnston, L. H., \& Milne, D. L. (2012). How do supervisee's learn during supervision? A grounded theory study of the perceived developmental process. The Cognitive Behaviour Therapist, 5, 1-23.

Kadushin A. (1968). Games people play in supervision. Social Work, 13, 23-32.

Kennerley, H., Kirk, J., \& Westbrook, D. (2017). An Introduction to Cognitive Behaviour Therapy: Skills and Applications. Sage.

Kolb, D. A. (1984). Experiential Learning: Experience as the Source of Learning and Development. Englewood Cliffs, USA: Prentice Hall.

Ladany, N., Mori, Y., \& Mehr, K. E. (2013). Effective and ineffective supervision. The Counseling Psychologist, 41, $28-47$.

Leahy, R. (2001). Overcoming Resistance in Cognitive Therapy. Guilford Press.

Liness, S., Beale, S., Lea, S., Byrne, S., Hirsch, C. R., \& Clark, D. M. (2019). The sustained effects of CBT training on therapist competence and patient outcomes. Cognitive Therapy and Research, 43, 631-641.

Meyer, J. M., Farrell, N. R., Kemp, J. J., Blakey, S. M., \& Deacon, B. J. (2014). Why do clinicians exclude anxious clients from exposure therapy? Behaviour Research and Therapy, 54, 49-53.

Milne, D. (2007). An empirical definition of clinical supervision. British Journal of Clinical Psychology, 46, 437-447.

Milne, D. (2008). CBT supervision: from reflexivity to specialization. Behavioural and Cognitive Psychotherapy, 36, 779.

Milne, D. (2020). Preventing harm related to CBT supervision: a theoretical review and preliminary framework. The Cognitive Behaviour Therapist, 13.

Milne, D., \& Dunkerley, C. (2010). Towards evidence-based clinical supervision: the development and evaluation of four CBT guidelines. The Cognitive Behaviour Therapist, 3.

Milne, D., \& James, I. (2000). A systematic review of effective cognitive-behavioural supervision. British Journal of Clinical Psychology, 39, 111-127.

Milne, D., \& Reiser, R. P. (2012). A rationale for evidence-based clinical supervision. Journal of Contemporary Psychotherapy, 42, 139-149. 
Milne, D. L. (2016). Guiding CBT supervision: how well do manuals and guidelines fulfil their promise? The Cognitive Behaviour Therapist, 9.

Milne, D. L., Leck, C., \& Choudhri, N. Z. (2009). Collusion in clinical supervision: literature review and case study in selfreflection. The Cognitive Behaviour Therapist, 2.

Milne, D. L., \& Reiser, R. P. (2014). SAGE: a scale for rating competence in CBT supervision. The Wiley International Handbook of Clinical Supervision, pp. 403-415.

Milne, D. L., Reiser, R. P., Cliffe, T., \& Raine, R. (2011). SAGE: preliminary evaluation of an instrument for observing competence in CBT supervision. The Cognitive Behaviour Therapist, 4.

Milne, D.L (2017) Evidence-Based CBT Supervision: Principles and Practice. John Wiley and Sons.

Moorey, S. (2013). The Interpersonal Cycle Worksheet. Cognitive Connections. Available at: http://www. cognitiveconnections.co.uk

Moorey, S., \& Byrne, S. (2019). Supervision and the Therapeutic Relationship. In Moorey, S., \& Lavender, A. (eds), The Therapeutic Relationship in Cognitive Behavioural Therapy. Sage.

Newman, C. F. (2013). Training cognitive behavioral therapy supervisors: didactics, simulated practice, and 'metasupervision'. Journal of Cognitive Psychotherapy, 27, 5-18.

Padesky, C. A. (1996). Developing cognitive therapist competency: teaching and supervision models. In Salkoskis, P. (ed), Frontiers of Cognitive Therapy, pp 266-292. New York, USA: Guilford Press.

Prasko, J., Vyskocilova, J., Slepecky, M., \& Novotny, M. (2012). Principles of supervision in cognitive behavioural therapy. Biomedical Papers of the Medical Faculty of Palacky University in Olomouc, 156.

Pretorius, W. M. (2006). Cognitive behavioural therapy supervision: recommended practice. Behavioural and Cognitive Psychotherapy, 34, 413.

Proctor, B. (1994). Supervision - competence, confidence, accountability. British Journal of Guidance \& Counselling, 22, 309-318.

Pugh, M. (2019a). Working with maladaptive therapist modes: an action experiential approach to supervision. Schema Therapy Bulletin, 3, 10-14.

Pugh, M. (2019b). A little less talk, a little more action: a dialogical approach to cognitive therapy. The Cognitive Behaviour Therapist, 12.

Pugh, M., \& Bell, T. (2020). Process-based chairwork: applications and innovations in the time of COVID-19. European Journal of Counselling Theory, Research, and Practice, 4, 1-8.

Pugh, M., \& Margetts, A. (2020). Are you sitting (un) comfortably? Action-based supervision and supervisory drift. The Cognitive Behaviour Therapist, 13, e17.

Rameswari, T., Hayes, B., \& Perera-Delcourt, R. (2021). Measuring therapist cognitions contributing to therapist drift: a qualitative study. The Cognitive Behaviour Therapist, 14.

Reiser, R. P., \& Milne, D. L. (2016). A survey of CBT supervision in the UK: methods, satisfaction and training, as viewed by a selected sample of CBT supervision leaders. The Cognitive Behaviour Therapist, 9.

Roscoe, J. (2021a). Maximising trainee cognitive behavioural therapists' use of clinical supervision: can a bespoke workshop help to broaden their horizons? Journal of Applied Psychology and Social Science, 6, 58-89.

Roscoe, J. (2021b). Therapist schema and supervisory drift: a conceptual model. BABCP Annual Conference, Belfast, Open Paper, 9 September 2021.

Roscoe, J., Taylor, J., Wilbraham, S., \& Harrington, R. (2019). CBT supervision at the coalface: how closely does the reality mirror the recommendations? An exploration of supervisor and supervisee experiences. BABCP Annual Conference, Bath, Poster Presentation, 4 September 2019.

Roth, A. D., \& Pilling, S. (2008). A competence framework for the supervision of psychological therapies. Available at: https:// www.ucl.ac.uk/pals/sites/pals/files/background_document_supervision_competences_july_2015.pdf (accessed 18 August 2011).

Roth, A. D., Pilling, S., \& Turner, J. (2010). Therapist training and supervision in clinical trials: implications for clinical practice. Behavioural and Cognitive Psychotherapy, 38, 291-302.

Schön, D. A. (1987). Educating the Reflective Practitioner: Toward a New Design for Teaching and Learning in the Professions. Jossey-Bass.

Scott, C. (2018). An Exploration of Burnout in Improving Access to Psychological Therapy (IAPT) Services: An Interpretative Phenomenological Analysis. Doctoral dissertation, University of the West of England.

Sherman, M. (2021). Therapist Factors and Effectiveness of Internet Enabled CBT (IECBT). Unpublished Master's dissertation, Bucks New University.

Simpson-Southward, C., Waller, G., \& Hardy, G. (2018). Supervisor practice when guiding therapists working with depression: the impact of supervisor and patient characteristics. The Cognitive Behaviour Therapist, 11.

Thwaites, R., \& Bennett-Levy, J. (2007). Conceptualizing empathy in cognitive behaviour therapy: making the implicit explicit. Behavioural and Cognitive Psychotherapy, 35, 591.

Townend, M., Iannetta, L., \& Freeston, M. H. (2002). Clinical supervision in practice: a survey of UK cognitive behavioural psychotherapists accredited by the BABCP. Behavioural and Cognitive Psychotherapy, 30, 485. 
Turpin, G., \& Wheeler, S. (2011). IAPT supervision guidance. Available at: http://www.iapt.nhs.uk/silo/files/iaptsupervision-guidance-revised-march-2011.pdf

Wainwright, N. A. (2010). The development of the Leeds Alliance in Supervision Scale (LASS): a brief sessional measure of the supervisory alliance. Available at: https://etheses.whiterose.ac.uk/1118/

Waller, G. (2009). Evidence-based treatment and therapist drift. Behaviour Research and Therapy, 47, 119-127.

Watkins Jr, C. E. (2020). The psychotherapy supervisor as an agent of transformation: To anchor and educate, facilitate and emancipate. American Journal of Psychotherapy, 73(2), 57-62.

Weck, F., Kaufmann, Y. M., \& Witthöft, M. (2017). Topics and techniques in clinical supervision in psychotherapy training. The Cognitive Behaviour Therapist, 10.

Wilcockson, M. D. (2020). Transition to cognitive behavioural therapy from different core professional backgrounds: three grounded theory studies. The Cognitive Behaviour Therapist, 13.

Wright, B., Williams, C., \& Garland, A. (2002). Using the Five Areas cognitive-behavioural therapy model with psychiatric patients. Advances in Psychiatric Treatment, 8, 307-315. doi: 10.1192/apt.8.4.307

Younge, J., \& Campbell, A. (2013). A qualitative study exploring the perceived impact of supervision training on cognitive therapy supervisor practice. The Cognitive Behaviour Therapist, 6.

Yourman, D. B. (2003). Trainee disclosure in psychotherapy supervision: The impact of shame. Journal of Clinical Psychology, 59(5), 601-609.

Cite this article: Roscoe J. Conceptualising and managing supervisory drift. The Cognitive Behaviour Therapist. https:// doi.org/10.1017/S1754470X21000350 